\title{
Effects of Aging Period Prior to Freezing on Meat Quality of Hanwoo Muscle (Longissimus dorsi)
}

\author{
Hyun-Wook Kim¹, Eui-Soo Lee ${ }^{2}$, Yun-Sang Choi ${ }^{3}$, Ji-Hun Choi ${ }^{1}$, Doo-Jeong Han ${ }^{1}$, Hack-Youn Kim ${ }^{4}$, \\ Dong-Heon Song ${ }^{1}$, Seul-Gi Choi ${ }^{1}$, and Cheon-Jei Kim ${ }^{1,4 *}$ \\ ${ }^{1}$ Department of Food Science and Biotechnology of Animal Resources, Konkuk University, Seoul 143-701, Korea \\ ${ }^{2} R \& D$ Center, Chicken University, Genesis Inc., Icheon 467-813, Korea \\ ${ }^{3}$ Food and Biological Resources Examination Division, Korean Intellectual Property Office, Daejeon 302-701, Korea \\ ${ }^{4}$ Research Institute for Meat Science and Culture, Konkuk University, Seoul 143-701, Korea
}

\begin{abstract}
This study was conducted to evaluate the effect of the aging period prior to freezing on the meat quality of Hanwoo longissimus dorsi (LD) muscle. Three different combinations of aging and freezing periods $(0 / 90,20 / 70$, and 40/50) were examined using LD muscle at $24 \mathrm{~h}$ postmortem under an identical storage time of $90 \mathrm{~d}$. The $\mathrm{pH}$ and lightness slightly increased with increasing aging period. However, there were no significant $(p>0.05)$ differences in redness and yellowness. The solitary freezing treatment $(0 / 90)$ had the significantly $(p<0.05)$ lowest moisture content. The un-aged treatment had a significantly $(p<0.05)$ higher total loss than the aged treatments due to an increase in thaw drip loss. The aging significantly improved the myofibrillar fragmentation index and shear force of Hanwoo LD muscle $(p<0.05)$. In addition, the aged treatments produced a higher flavor, tenderness, juiciness, and overall acceptability relative to un-aged treatment. However, there was no significant $(p>0.05)$ difference in shear force and sensorial properties between 20 and $40 \mathrm{~d}$ aging prior to freezing. Therefore, $20 \mathrm{~d}$ aging prior to freezing may be a sufficiently effective strategy to improve the tenderness and sensorial properties of Hanwoo LD muscle
\end{abstract}

Key words: aging, freezing, Hanwoo, tenderness

\section{Introduction}

After slaughter, the muscle of mammals, such as beef, hog, and lamb etc., begin undergoing various biochemical changes such as the depletion of ATP (adenosine triphosphate) and glycogen under anaerobic conditions. These changes result in rigor-mortis of pre-rigor muscle, which eventually decreases the tenderness due to changes in $\mathrm{pH}$ and the contraction of myofibrillar proteins (Faustman, 1994; Savell et al., 2005). Meat aging is one of the most commonly used methods to enhance the toughness caused by rigor-mortis and to improve the taste and flavor (Sitz et al., 2006). According to Faustman (1994), the meat tenderness during aging is affected by two proteolytic enzymes and specific conditions ( $\mathrm{pH}$ and temperature) that influence the enzymatic activity are extremely impor-

\footnotetext{
*Corresponding author: Cheon Jei Kim, Department of Food Science and Biotechnology of Animal Resources, Konkuk University, Seoul 143-701, Korea. Tel: 82-2-450-3684, Fax: 82-2-444-6695, E-mail: kimcj@konkuk.ac.kr
}

tant during meat aging. Moreover, meat aging requires additional storage space, labor, and a refrigerator facility to control the temperature and relative humidity. Thus, many studies have been conducted to determine the optimal aging conditions and to save production cost as well as to improve meat quality (Crouse and Koohmaraie, 1990).

Many retailed meat is frozen to maintain meat quality and to improve shelf stability. Koohmaraie (1990) suggested that activity of CDP (calcium-dependent proteases) could be maintained under frozen conditions by comparing aged beef without freezing and aged beef after freezing and thawing. Cohen (1984) conducted a similarly designed experiment to evaluate the frozen parts of beef, and their results indicated that aging after freezing and thawing was important. Farouk et al. (2009) and Wiklund et al. (2009) indicated that freezing of sufficiently aged meat can improves the increase in toughness and drip loss. Shanks et al. (2002) reported that freezing reduced the Warner-Bratzler shear force values of beef steak. Kim et al. (2011) examined the effects of aging prior to freez- 
ing and packaging after a freeze-thaw cycle on color stability of ovine muscle. However, the effects of different combinations of aging and freezing periods under identical storage conditions after slaughter on meat quality have not been studied. In addition, studies on the aging of Hanwoo have been limited to examining the effect of aging temperature, period, and packing method (Choi et al., 1995; Kim et al., 2007). Therefore, the objective of this study was to evaluate the effects of the aging period prior to freezing on the meat quality of Hanwoo longissimus dorsi muscle.

\section{Materials and Methods}

\section{Raw material collection and sample preparation}

A total of nine Hanwoo cows (each of three Hanwoo cows in three replications), which ranged in age from 24 to 27 mon (average live weights: $570.2 \mathrm{~kg}$; average carcass weights: $320.5 \mathrm{~kg}$ ), were obtained from the local municipal slaughterhouse. The processing of carcasses was as following: After splitting and bleeding, the carcasses were washed and immediately moved to a chilling room $\left(2 \pm 1^{\circ} \mathrm{C}\right) .24 \mathrm{~h}$ post-mortem, the carcasses were judged by an official grader according to the Korean carcass grading procedure (National Livestock Cooperatives Federation, NLCF, 1998). Based on this grading system, carcasses classified as $1^{++} \mathrm{A}$ (quality and yield grade) were obtained to collect longissimus dorsi (LD) muscle. Samples of LD were taken from between the 12th and 13th rib of each carcass, and were sliced into a thickness of about $2.5 \mathrm{~cm}$ to maintain the original shape of the muscle. All samples were vacuum-packaged in polyethylene bags and divided into three groups. Each group was treated as follows (aging period/freezing period): 0/90 (un-aged treatment $)=$ immediately freezing in a $-20^{\circ} \mathrm{C}$ freezer during $90 \mathrm{~d}$ without aging period in refrigerator, 20/70 (intermediate aged treatment) $=20 \mathrm{~d}$ of aging period in a $2^{\circ} \mathrm{C}$ refrigerator, followed by $70 \mathrm{~d}$ storage at $-20^{\circ} \mathrm{C}$, and $40 / 50$ (long-term aged treatment) $=40 \mathrm{~d}$ of aging in a $2^{\circ} \mathrm{C}$ refrigerator, followed by $50 \mathrm{~d}$ storage at $-20^{\circ} \mathrm{C}$ ). The sample at post-mortem $24 \mathrm{~h}$ is marked $0 \mathrm{~d}$ of aging period (unaged), and all samples were stored using different combinations of aging and freezing time over the same $90 \mathrm{~d}$ storage period.

Each frozen LD sample was unpacked to measure the weight of the frozen sample, and then was repacked using a vacuum package machine. The samples were thawed in running water (approximately $15 \pm 1^{\circ} \mathrm{C}$ ) for analysis of meat quality. To evaluate the thawing time, the center temperature of the sample was pre-tested using a digital thermometer (Tes-1305, Tes Electrical Corp., Taiwan) equipped with a data logger (RS-232, Tes Electrical Corp., Taiwan) by inserting an iron constantan thermocouple. The thawing time was calculated by measuring the time required for the sample to reach $4^{\circ} \mathrm{C}$ using these pieces of equipment. Each frozen-thawed sample was unpacked to measure the $\mathrm{pH}$, instrumental color, moisture content, sarcomere length, myofibrillar fragmentation index (MFI), and nucleotide relative compounds. All analysis was performed in triplicate.

\section{pH measurements}

The $\mathrm{pH}$ values of frozen-thawed Hanwoo muscle were determined with a $\mathrm{pH}$ meter (Model 340, Mettler-Toledo $\mathrm{GmbH}$, Switzerland). The $\mathrm{pH}$ values of samples were measured by blending a $5 \mathrm{~g}$ sample with $20 \mathrm{~mL}$ distilled water for $60 \mathrm{~s}$ in a homogenizer at 8,000 rpm (Ultra-Turrax SK15, Janke \& Kunkel, Germany).

\section{Instrumental color evaluation}

Instrumental color were determined using a colorimeter (Minolta Chroma meter CR-210, Japan; illuminate C, calibrated with a white plate, CIE $L^{*}=+97.83, \mathrm{CIE} \mathrm{a}^{*}=-0.43$, $\left.\mathrm{CIE}^{*}=+1.98\right)$. Five measurements for each of five locations on surface of thawed Hanwoo muscle were taken. CIE L* (lightness), CIE a* (redness), and CIE b* (yellowness) values were recorded.

\section{Moisture content}

Moisture content of the samples was determined using AOAC (2000) procedures. Moisture content (950.46B, oven air-drying method) was determined by weight loss after $12 \mathrm{~h}$ of drying at $105^{\circ} \mathrm{C}$ in a drying oven (SW-90D, Sang Woo Scienctific Co., Korea).

\section{Thaw drip, cooking, and total loss}

Thaw drip loss (\%) was determined for individual samples by calculating the weight differences between frozen sample (approximately $250 \mathrm{~g}$ ) and thawed sample. After thaw drip loss determination, the samples were bagged within polyethylene bags and then immersed in a $75^{\circ} \mathrm{C}$ water bath (Model 10-101, Daehan Co., Korea) for 30 min and cooled at room temperature for $2 \mathrm{~h}$. After cooling, the cooked samples were weighed. Cooking loss (\%) was determined by weighing the meat before and after cooking. Also, total loss (\%) was determined for individual samples by calculating the weight differences between frozen sample and cooked sample. Each expression is as 
in the following:

$$
\begin{aligned}
& \text { Thaw drip loss }(\%)=\frac{(A-B)}{A} \times 100 \\
& \text { Cooking loss }(\%)=\frac{(B-C)}{B} \times 100 \\
& \text { Total loss }(\%)=\frac{(A-C)}{A} \times 100
\end{aligned}
$$

where, $A=$ the weight of frozen sample, $B=$ the weight of thawed sample, $C=$ the weight of cooked sample

\section{Sarcomere length}

Sarcomere length of each frozen-thawed sample was determined by neon laser diffraction method (Voyle, 1971). Briefly, about $500 \mathrm{mg}$ of muscle samples were carefully cut with scissors and inserted in $2 \%$ glutaraldehyde solution with $2 \%$ glucose in $0.1 \mathrm{M}$ phosphate buffer, $\mathrm{pH}$ 7.0. The samples were fixed at $4^{\circ} \mathrm{C}$ for $30 \mathrm{~min}$, and then sarcomere length was measured using Helium-NeonLaser (model No. 212-2; Spectra-Physics, USA).

\section{Myofibrillar fragmentation index (MFI)}

Myofibrils was obtained according to the method of Olson et al. (1976) using MFI buffer (20 mM K $\mathrm{HPO}_{4} /$ $\mathrm{KH}_{2} \mathrm{PO}_{4}, \mathrm{pH} 7.0,100 \mathrm{mM} \mathrm{KCl}, 1 \mathrm{mM}$ EDTA, $1 \mathrm{mM}$ $\mathrm{NaN}_{3}$ ). The myofibrils were suspended in MFI buffer. An aliquot of myofibril suspension was diluted with the MFI buffer to $0.5 \mathrm{mg} / \mathrm{mL}$ protein concentration and the absorbance of this suspension measured at $540 \mathrm{~nm}$. MFI values were recorded as absorbance units per $0.5 \mathrm{mg} / \mathrm{mL}$ myofibril protein concentration multiplied by 200 .

\section{Shear force}

For the determination of shear force, each sample was cooked individually polyethylene bags immersed in a $75^{\circ} \mathrm{C}$ water bath (Model 10-101, Daehan Co., Korea) for $30 \mathrm{~min}$. After cooking, the cooked samples were cooled at room temperature for $3 \mathrm{~h}$. Shear force values were determined with a Warner-Bratzler hear attachment (Vtype blade set) on a texture analyzer (TA-XT2i, Stable Micro Systems Ltd., England). Test speeds were set at 2 $\mathrm{mm} / \mathrm{s}$. Data were collected and analyzed from the shear force values to obtain the maximum force required to shear through each sample. A sample was cut from each cooked Hanwoo sample, paralleled to the muscular fiber $(1.0 \times 1.0 \times 4.0 \mathrm{~cm})$.

\section{Nucleotide related compounds}

The concentrations nucleotide related compounds in frozen-thawed Hanwoo LD muscle were determined using a modification of procedures by Iwamoto et al. (1987) and Lee et al. (1984). The HPLC analysis was performed on a Model HPLC 1100 series (Agilent Technologies, USA). The chromatographic separation was performed using a $\mathrm{C}_{18}$ column (3.9 mm i.d. $\times 300 \mathrm{~mm}$, $\mu$ Bondapak, Waters Associated Inc., USA) at $40^{\circ} \mathrm{C} .10 \mu \mathrm{L}$ of sample were injected into the HPLC system, and 1\% triethylamine phosphate buffer ( $\mathrm{pH}$ 6.5) was used as a mobile phase. The separated compounds were monitored at 254 $\mathrm{nm}$, and quantitation of each peak was performed by means of individually standard curves.

\section{Sensory evaluation}

The cooked samples were evaluated for color, flavor, juiciness, tenderness, and overall acceptability. The cooked samples as previously described were cooled to the room temperature at $25 \pm 1^{\circ} \mathrm{C}$ and cut and served to the panelists in random order. The sensory evaluations were performed by the panelists under fluorescence lighting. Panelists were instructed to cleanse their palates between samples using water. The color, flavor, and overall acceptability ( 1 =extremely undesirable, $10=$ extremely desirable), tenderness ( $1=$ extremely tough, $10=$ extremely tender), juiciness ( $1=$ extremely dry, $10=$ extremely juicy) of the cooked samples were evaluated using a 10-point descriptive scale. The panel consisted of 12 members from the Department of Food Sciences and Biotechnology of Animal Resources at Konkuk University in Korea.

\section{Statistical analysis}

A 3 (different combination between aging and freezing period) factorial treatments with three replicates was employed, with treatments (different combination between aging and freezing period) as main effects using two-way analysis of variance (ANOVA). An analysis of variance were performed on all the variables measured using the General Linear Model (GLM) procedure of the SAS statistical package (SAS Institute, Inc., 1999). Duncan's multiple range test $(p<0.05)$ was used to determine differences between treatment means.

\section{Results and Discussion}

\section{The pH value, instrumental color, moisture con- tents}

The effects of aging period prior to freezing on the $\mathrm{pH}$ value, instrumental color, and moisture content of frozenthawed Hanwoo longissimus dorsi (LD) muscle are 
Table 1. Effects of aging period prior to freezing on the $\mathrm{pH}$, instrumental color, and moisture content of frozenthawed Hanwoo muscle (longissimus dorsi)

\begin{tabular}{lccc}
\hline \hline \multirow{2}{*}{ Traits } & \multicolumn{3}{c}{ Aging period (d)/Freezing period (d) ${ }^{1)}$} \\
\cline { 2 - 4 } & $0 / 90$ & $20 / 70$ & $40 / 50$ \\
\hline $\mathrm{pH}$ & $5.44 \pm 0.05^{2) \mathrm{B}}$ & $5.55 \pm 0.08^{\mathrm{A}}$ & $5.57 \pm 0.10^{\mathrm{A}}$ \\
$\mathrm{CIE} \mathrm{L}^{*}$ value & $39.41 \pm 1.49^{\mathrm{B}}$ & $40.29 \pm 1.07^{\mathrm{AB}}$ & $40.88 \pm 1.56^{\mathrm{A}}$ \\
$\mathrm{CIE} \mathrm{a}^{*}$ value & $13.74 \pm 0.92$ & $13.84 \pm 1.50$ & $14.05 \pm 1.15$ \\
$\mathrm{CIE} \mathrm{b}^{*}$ value & $2.99 \pm 0.52$ & $3.20 \pm 0.60$ & $3.26 \pm 0.47$ \\
Moisture content (\%) $55.24 \pm 2.42^{\mathrm{B}}$ & $58.18 \pm 2.68^{\mathrm{A}}$ & $58.92 \pm 2.54^{\mathrm{A}}$ \\
\hline${ }^{1)}$ All samples were pre-cooled for $24 \mathrm{~h}$ after slaughter in a $2^{\circ} \mathrm{C}$ \\
refrigerator, and the sample at post-mortem 24 h is marked as 0 \\
d of aging period (un-aged). \\
${ }^{2)}$ All values are mean \pm SD of three replicates. \\
A,B Means within a row with different letters are significantly dif- \\
ferent $(p<0.05)$.
\end{tabular}

shown in Table 1 . The un-aged treatment $(0 / 90)$ had a significantly $(p<0.05)$ lower $\mathrm{pH}$ value than that of the aged treatments $(20 / 70$ and 40/50) and no significantly ( $p>$ 0.05 ) difference in the $\mathrm{pH}$ value was observed between $20 \mathrm{~d}$ aging and $40 \mathrm{~d}$ aging prior to freezing. Similarly, Boakey and Mittal (1993), Choi et al. (1995), and Han et al. (1996) reported that the $\mathrm{pH}$ value of beef increased with an increase in the aging period. Kim et al. (2007) found that the maximum $\mathrm{pH}$ value of Hanwoo LD muscle during aging was affected by the aging temperature, and reported the there are no significantly $(p>0.05)$ differences in $\mathrm{pH}$ value above an aging period of $21 \mathrm{~d}$ at $0^{\circ} \mathrm{C}$. Boakye and Mittal (1993) indicated that there were positive correlations between $\mathrm{pH}$ and aging time $(p<0.001$, $r=0.44$ ) for $\mathrm{LD}$ muscle during $16 \mathrm{~d}$ at $2^{\circ} \mathrm{C}$. Farouk and Swan (1998) reported that the increase in the ultimate $\mathrm{pH}$ of beef during storage was associated with an increase in the free amino acids content. According to Choi et al. (1995), the increase in free amino acids and non-protein nitrogen compounds, which are formed through enzymatic reactions with meat protein, was cause for the increase in $\mathrm{pH}$ during meat aging. In addition, Kim et al. (1988) reported that $\mathrm{pH}$ of frozen beef increased by 0.1 0.2 during $16 \mathrm{wk}$. In previous studies, both aging and freezing periods led to an increase in the $\mathrm{pH}$ value. Based on our results, a longer time of aging contributed to a high $\mathrm{pH}$ value of Hanwoo LD muscle under identical storage periods after slaughter.

The lightness (CIE L ${ }^{*}$ ) slightly increased with an increase in the aging period. However, there was only a significant different $(p<0.05)$ between un-aged treatment $(0 / 90)$ and long-term aged treatment (40/50). An increase in the lightness of aged beef has been reported in many studies
(Boakye and Mittal, 1996; Gasperlin et al., 2001). Kim et al. (2011) suggested that an increase in the free water content resulted in an increase in the lightness on the surface of meat, and reported that the lower lightness of unaged muscle (similarly designed 0/90 treatment in our study) was associated with activity of mitochondrial respiratory enzymes due to the decrease in oxygenation of myoglobin. Moreover, an increase in oxygenation of myoglobin within aged meat compared with un-aged meat (only freezing) resulted in an increase in the redness (CIE a ${ }^{*}$ ). As a similar result, Claus et al. (1984) indicated that the increase in oxymyoglobin content due to collapse of muscle fiber influences the improvement of meat color during aging period. We observed a similar trend for changes in the redness values. However, there were no significant $(p>0.05)$ differences in redness and yellowness (CIE b*) among the different treatments.

The un-aged treatment $(0 / 90)$ showed a significant $(p<$ $0.05)$ lower moisture content $(p<0.05)$ than aged treatments (20/70 and 40/50), however, there were no significant $(p>0.05)$ differences in moisture content between 20 and $40 \mathrm{~d}$ of aging period. Generally, the decrease in moisture content of frozen-thawed meat is caused by a drip loss (Daudin, 1992). Our results, the lower moisture content of the only freezing treatment, results from the increase in drip loss due to the longer freezing period.

\section{Thaw drip loss, cooking loss, and total loss}

The effects of aging periods prior to freezing on the drip, cooking, and total loss of frozen-thawed Hanwoo LD muscle are shown in Table 2. Thaw drip loss was measured to evaluate the amount of released moisture during thawing under running water. The un-aged treatment had a significantly $(p<0.05)$ higher thaw drip loss

Table 2. Effects of aging period prior to freezing on the thaw drip loss, cooking loss, and total loss of frozen-thawed Hanwoo muscle (longissimus dorsi)

\begin{tabular}{lccc}
\hline \hline \multirow{2}{*}{ Traits } & \multicolumn{3}{c}{ Aging period (d)/Freezing period (d) $)^{1)}$} \\
\cline { 2 - 4 } & $0 / 90$ & $20 / 70$ & $40 / 50$ \\
\hline Thaw drip loss (\%) & $4.54 \pm 0.21^{2) \mathrm{A}}$ & $2.93 \pm 0.58^{\mathrm{B}}$ & $2.26 \pm 0.65^{\mathrm{B}}$ \\
Cooking loss (\%) & $23.16 \pm 0.63$ & $24.66 \pm 0.44$ & $24.59 \pm 0.95$ \\
Total loss ${ }^{3)}(\%)$ & $27.03 \pm 0.44^{\mathrm{A}}$ & $25.13 \pm 0.89^{\mathrm{B}}$ & $25.46 \pm 1.21^{\mathrm{B}}$ \\
\hline${ }^{1}$ All samples were pre-cooled for $24 \mathrm{~h}$ after slaughter in a $2^{\circ} \mathrm{C}$ \\
refrigerator, and the sample at post-mortem $24 \mathrm{~h}$ is marked as 0 \\
d of aging period (un-aged). \\
${ }^{2)}$ All values are mean \pm SD of three replicates. \\
${ }^{3)}$ Total loss: percentage value to differences in weight between \\
frozen sample and cooked sample. \\
A,B Means within a row with different letters are significantly dif- \\
ferent $(p<0.05)$.
\end{tabular}


than aged treatments but there was no significant $(p>$ 0.05 ) differences between aging times of 20 and $40 \mathrm{~d}$. On the contrary, Jung et al. (1998) reported that the thaw drip loss of vacuum packaged beef over a storage time of $60 \mathrm{~d}$ increased. According to Fennema (1973), protein denaturation due to damage to cell membranes during freezing resulted in a decrease in water holding capacity, and caused an increase in the thaw drip loss. In regards to cooking loss, the aged treatments show a higher cooking loss than un-aged treatment. However, there were no significant $(p>0.05)$ differences among the all treatments, which was probably due to the fact that a considerable amount of moisture was removed during the thawing process. In previously studies, an increase in the aging period without freezing was reported to result in an increase in cooking loss (Boakye and Mittal, 1993; Kim et al., 2007). In addition similar results were also observed during the freezing process (Cohen, 1984; Jung et al., 1998). Kim et al. (2007) suggested that an increase in cooking loss with aging time resulted from myofibrillar fragmentation. For total loss, which means total amount of released moisture by thawing and cooking, un-aged treatment had significantly $(p<0.05)$ higher total loss than all other treatments. Kim et al. (2007) reported a significant increase in purge loss for Hanwoo carcass with aging time up to $49 \mathrm{~d}$. Thus, an increase in both aging and freezing resulted in a loss of moisture. In our study, an increase in the freezing period had a great effect on total loss due to thaw drip loss than the aging period.

\section{Sarcomere length, myofibrillar fragmentation index (MFI), and shear force}

Aging has been shown to be an effective method to improve meat tenderness (Dransfield, 1994), sarcomere length, MFI, and shear force, which can be used as a measure of meat tenderness. The sarcomere length of unaged Hanwoo LD muscle $(1.73 \mu \mathrm{m})$ was lower than those of aged Hanwoo muscle; however, there were no significant $(p>0.05)$ differences between $20 \mathrm{~d}(1.92 \mu \mathrm{m})$ aged and $40 \mathrm{~d}(1.93 \mu \mathrm{m})$ aged Hanwoo muscle (Table 3$)$. Similarly, Wheeler and Koohmaraie (1994) reported that the sarcomere length of ovine longissimus muscle decreased up to $24 \mathrm{~h}$ postmortem and then increased up to $14 \mathrm{~d}$ postmortem at $1{ }^{\circ} \mathrm{C}$ in a chill cooler. The myofibrillar fragmentation index (MFI) is a good indicator of the extent of proteolysis due to the vicinity of the Z-disc, and this parameter is affected by the storage periods and temperature (Olson and Parrish, 1976; Parrish et al., 1973). In many previous studies, MFI was used to evaluate and predict
Table 3. Effects of aging period prior to freezing on the sarcomere length, $\mathrm{MFI}^{1}$, and shear force of frozenthawed Hanwoo muscle (longissimus dorsi)

\begin{tabular}{|c|c|c|c|}
\hline \multirow{2}{*}{ Traits } & \multicolumn{3}{|c|}{ Aging period $(\mathrm{d}) /$ Freezing period $(\mathrm{d})^{2)}$} \\
\hline & $0 / 90$ & $20 / 70$ & $40 / 50$ \\
\hline Sarcomere length $(\mu \mathrm{m})$ & $1.73 \pm 0.09^{3) \mathrm{B}}$ & $1.92 \pm 0.19^{\mathrm{A}}$ & $1.93 \pm 0.10^{\mathrm{A}}$ \\
\hline MFI & $35.20 \pm 1.24^{\mathrm{C}}$ & $78.52 \pm 2.44^{\mathrm{B}}$ & $97.48 \pm 3.18^{\mathrm{A}}$ \\
\hline Shear force $(\mathrm{kg})$ & $4.80 \pm 0.69^{\mathrm{A}}$ & $3.62 \pm 0.35^{\mathrm{B}}$ & $3.54 \pm 0.58^{\mathrm{B}}$ \\
\hline \multicolumn{4}{|c|}{$\begin{array}{l}\text { 1) MFI: myofibrillar fragmentation index. } \\
\text { 2) All samples were pre-cooled for } 24 \mathrm{~h} \text { after slaughter in a } 2^{\circ} \mathrm{C} \\
\text { refrigerator, and the sample at post-mortem } 24 \mathrm{~h} \text { is marked as } 0 \\
\mathrm{~d} \text { of aging period (un-aged). } \\
{ }^{3)} \text { All values are mean } \pm \mathrm{SD} \text { of three replicates. } \\
{ }^{\mathrm{A}-\mathrm{C}} \text { Means within a row with different letters are significantly dif- } \\
\text { ferent }(p<0.05) \text {. }\end{array}$} \\
\hline
\end{tabular}

meat tenderness (Han et al., 1996), and a high positive correlation between MFI and shear force $(p<0.0001, r=$ -0.53 ) in aged muscle was observed by Kim et al. (2007). In our study, MFI significantly $(p<0.05)$ increased with an increase in the aging period. Similar results were observed by Kim et al. (2007), who reported that the MFI in longissimus Hanwoo muscle increased with an increase in aging time over $49 \mathrm{~d}$ at 0 or $4^{\circ} \mathrm{C}$. Jung et al. (1998) also reported that MFI of vacuum packaging beef slightly increase during freezing. Wheeler and Koohmaraie (1999) found that the sarcomere length directly influenced the meat tenderness but this effect was not related to proteolysis during aging. Smulders et al. (1990) observed a high negative correlation between sarcomere length and shear force in only the un-aged muscle. Our results also showed that despite the differences in MFI (proteolysis index), the sarcomere length between an aging time of 20 and 40 $\mathrm{d}$ was similar. An increase in aging time influenced the development of shear force in frozen-thawed Hanwoo LD muscle. However, there was no significant $(p>0.05)$ difference between an aging time of 20 and $40 \mathrm{~d}$ prior to freezing.

\section{Nucleotide related compounds}

The development of flavor and improved meat tenderness in aged meat are important effects of meat aging (Sitz et al., 2006). Immediately after slaughter, the muscle still contains high levels of ATP (adenosine triphosphate) but is depleted to ADP (adenosine diphosphate), AMP (adenosine monophosphate), IMP (inosine monophosphate), inosine, and Hx (hypoxanthine) due to continuous post-mortem metabolism (Faustman, 1994). IMP and inosine are known to significantly affect meat flavor (Calkins et al., 1982). The effects of aging period prior to 
Table 4. Effects of aging period prior to freezing on the nucleotide related compounds of frozen-thawed Hanwoo muscle (longissimus dorsi)

\begin{tabular}{llll}
\hline \hline \multirow{2}{*}{ Traits } & \multicolumn{3}{c}{ Aging period $(\mathrm{d}) /$ Freezing period $(\mathrm{d})^{1)}$} \\
\cline { 2 - 4 } & \multicolumn{1}{c}{$0 / 90$} & \multicolumn{1}{c}{$20 / 70$} & $40 / 50$ \\
\hline $\mathrm{IMP}^{3)}(\mu \mathrm{mole} / \mathrm{g})$ & $3.27 \pm 0.33^{2) \mathrm{A}}$ & $2.51 \pm 0.03^{\mathrm{B}}$ & $1.06 \pm 0.14^{\mathrm{C}}$ \\
Inosine $\left.^{\mathrm{C}} \mu \mathrm{mole} / \mathrm{g}\right)$ & $1.19 \pm 0.04$ & $1.18 \pm 0.07$ & $1.14 \pm 0.08$ \\
$\mathrm{Hx}^{4)}(\mu \mathrm{mole} / \mathrm{g})$ & $2.88 \pm 0.22^{\mathrm{C}}$ & $3.83 \pm 0.18^{\mathrm{B}}$ & $5.29 \pm 0.18^{\mathrm{A}}$
\end{tabular}

${ }^{1)}$ All samples were pre-cooled for $24 \mathrm{~h}$ after slaughter in a $2^{\circ} \mathrm{C}$ refrigerator, and the sample at post-mortem $24 \mathrm{~h}$ is marked as 0 $\mathrm{d}$ of aging period (un-aged).

${ }^{2)}$ All values are mean $\pm \mathrm{SD}$ of three replicates.

${ }^{3)}$ IMP: inosine monophosphate.

${ }^{4)} \mathrm{Hx}$ : hypoxanthine

${ }^{\mathrm{A}-\mathrm{C}}$ Means within a row with different letters are significantly different $(p<0.05)$.

freezing on the nucleotide relative compounds (IMP, inosine, and $\mathrm{Hx}$ ) of frozen-thawed Hanwoo LD muscle are shown in Table 4. ATP was not detected in all treatments (data not shown). The amount of IMP decreased significantly, but the amount of $\mathrm{Hx}$ increased significantly $(p<0.05)$ with aging. Also, there were no significant $(p>0.05)$ differences in the amount of inosine among all the treatments. Generally, the amount of IMP reached a maximum level after slaughter, and then continuously decreased due to break down into inosine and $\mathrm{Hx}$ (Yano et al., 1995). For these reasons, our results showed that a decreased IMP content was associated with an increased Hx content. Similarly, Shin et al. (1994) reported that the

Table 5. Effects of aging periods prior to freezing on the sensorial properties of frozen-thawed Hanwoo muscle (longissimus dorsi)

\begin{tabular}{lccc}
\hline \multirow{2}{*}{ Traits $^{2)}$} & \multicolumn{3}{c}{ Aging period (d)/Freezing period (d) ${ }^{1)}$} \\
\cline { 2 - 4 } & $0 / 90$ & $20 / 70$ & $40 / 50$ \\
\hline Color & $8.00 \pm 0.76^{3)}$ & $8.00 \pm 0.85$ & $7.87 \pm 0.83$ \\
Flavor & $7.53 \pm 0.52^{\mathrm{B}}$ & $8.33 \pm 0.82^{\mathrm{A}}$ & $8.53 \pm 0.74^{\mathrm{A}}$ \\
Tenderness & $7.47 \pm 0.64^{\mathrm{B}}$ & $8.40 \pm 0.63^{\mathrm{A}}$ & $8.53 \pm 0.52^{\mathrm{A}}$ \\
Juiciness & $7.20 \pm 0.68^{\mathrm{B}}$ & $8.40 \pm 0.63^{\mathrm{A}}$ & $8.47 \pm 0.64^{\mathrm{A}}$ \\
Overall acceptability & $7.40 \pm 0.74^{\mathrm{B}}$ & $8.27 \pm 0.59^{\mathrm{A}}$ & $8.40 \pm 0.74^{\mathrm{A}}$ \\
\hline
\end{tabular}

\footnotetext{
${ }^{1)}$ All samples were pre-cooled for $24 \mathrm{~h}$ after slaughter in a $2^{\circ} \mathrm{C}$ refrigerator, and the sample at post-mortem $24 \mathrm{~h}$ is marked as 0 $\mathrm{d}$ of aging period (un-aged).

2) Traits: scores based on a 10 point scale, where $1=$ extremely undesirable and $10=$ extremely desirable for color, flavor, and overall acceptability; $1=$ extremely tough and $10=$ extremely tender for tenderness; $1=$ extremely dry and $10=$ extremely juicy for juiciness

${ }^{3)}$ All values are mean $\pm \mathrm{SD}$ of three replicates.

${ }^{\mathrm{A}, \mathrm{B}}$ Means within a row with different letters are significantly different $(p<0.05)$.
}

highest IMP content occurred $1 \mathrm{~d}$ after slaughter and then decreased.

\section{Sensorial properties}

The effects of aging periods prior to freezing on the sensorial properties of frozen-thawed Hanwoo LD muscle are shown in Table 5. Aged treatments produced a significantly $(p<0.05)$ higher flavor, tenderness, juiciness, and overall acceptability relative to un-aged Hanwoo treatment. However, there was no significant $(p>0.05)$ difference in apparent color among all the treatments. Similarly, Kim et al. (2007) reported that the sensorial scores on tenderness, flavor, and juiciness of Hanwoo longissimus muscle increased during aging for $28 \mathrm{~d}$ at 0 and $4^{\circ} \mathrm{C}$, which suggests that there is a positive correlation between shear force and sensorial tenderness. In regards to flavor, although the amounts of IMP and Hx between 20 and $40 \mathrm{~d}$ aging treatments differed (Table 4), there was no significant $(p>0.05)$ difference in sensorial flavor. According to Cho et al. (2007), the amount of IMP in beef is not directly related to its taste. Choi et al. (1995) reported that nucleotide compounds and specific amino acid (L-glutamate) produced a synergistic effect on flavor.

In conclusions, our results suggest that the different combinations of aging and freezing time under an identical total storage time ( $90 \mathrm{~d}$ ) had an effect on the quality of Hanwoo longissimus dorsi muscle. However, there were no differences in shear force and sensorial properties between $20 \mathrm{~d}$ of aging followed by $70 \mathrm{~d}$ of freezing and $40 \mathrm{~d}$ of aging followed by $50 \mathrm{~d}$ of freezing. Therefore, if consumers do not use an additional aging period after thawing, $20 \mathrm{~d}$ of aging before freezing may be a sufficiently effective strategy for improving tenderness and sensorial properties.

\section{Acknowledgement}

This reseach was supported by the Brain Korean 21 (BK21) Project from the Ministry of Education and Human Resources Development, Republic of Korea.

\section{References}

1. AOAC (2000) Official methods of analysis. 17th ed, Associations of Official Analytical Chemists, Arlington, VA, USA. Method 950.46B.

2. Boakye, K. and Mittal, G. S. (1993) Changes in $\mathrm{pH}$ and water holding properties of longissimus dorsi muscle during beef ageing. Meat Sci. 34, 335-349.

3. Boakye, K. and Mittal, G. S. (1996) Changes in colour of beef 
M. longissimus dorsi muscle during ageing. Meat Sci. 42, 347-354.

4. Calkins, C. R., Dutson, T. R., Smith, G. C., and Carpenter, Z. L. (1982) Concentration of creatine phosphate, adenine nucleotides and their derivatives in electrically stimulated and nonstimulated beef muscle. J. Food Sci. 47, 1350-1353.

5. Cho, S. H., Kim, J. H., Seong, P. N., Choi, Y. H., Park, B. Y., Lee, Y. J., In, T. S., Chun, S. Y., and Kim, Y. K. (2007) Cholesterol, free amino acid, nucleotide-related compounds, and fatty acid composition of Korean Hanwoo bull beef. Korean J. Food Sci. Ani. Resour. 27, 440-449.

6. Choi, Y. I., Kim, Y. K., and Lee, C. L. (1995) Effects of packaging method and aging temperature on color, tenderness and storage characteristics of Korean beef. Korean J. Anim. Sci. 37, 639-650.

7. Claus, J. R., Kropt, D. H., Hunt, M. C., Kaster, C. L., and Dikman, M. C. (1984) Effects of beef carcass electrical stimulation and hot bonning on muscle display color of polyvinylchloride packaged steaks. J. Food Sci. 49, 1021-1023.

8. Cohen, T. (1984) Aging of frozen parts of beef. J. Food Sci. 49, 1174-1177.

9. Crouse, J. D. and Koohmaraie, M. (1990) Effect of freezing of beef on subsequent postmortem aging and shear force. $J$. Food Sci. 55, 573-574.

10. Daudin, J. D. (1992) Freezing. In: Technology of meat and meat products. Girard, J. P. (ed) Ellis Horwood Limited, England, pp. 5-31.

11. Farouk, M. M. and Swan, J. E. (1998) Effect of muscle condition before freezing and simulated chemical changes during frozen storage on the $\mathrm{pH}$ and colour of beef. Meat Sci. 50, 245-256.

12. Farouk, M., Wiklund, E., Stuart, A., and Dobbie, P. (2009) Ageing prior to freezing improves the colour of frozenthawed beef and venison. Proceed. 55th ICoMST, Copenhagen, Denmark, pp. 786-790.

13. Faustman, C. (1994) Postmortem changes in muscle foods. In: Muscle foods: meat poultry and seafood technology. Kinsman, D. M., Kolula, A. W., and Breidenstein, C. (eds) Chapman and Hall Publishers, NY, pp. 63-78.

14. Fennema, O. (1973) Water and ice: Low temperature preservation of foods and living matter. Marcel Dekker, Inc., NY, pp. 1-77.

15. Gasperlin, L., Zlender, B., and Abram, V. (2001) Colour of beef heated to different temperatures as related to meat ageing. Meat Sci. 59, 23-30.

16. Han, G. D., Kim, D. G., Kim, S. M., Ahn, D. H., and Sung, S. K. (1996) Effects of aging on the physico-chemical and morphological properties in the Hanwoo beef by the grade. Korean J. Anim. Sci. 38, 589-596.

17. Iwamoto, M., Yamanaka, H., Watabe, S., and Hashimoto, K. (1987) Effect of storage temperature on rigor-mortis and ATP degradation in place paralichthys olivaceus muscle. $J$. Food Sci. 53, 1514-1517.

18. Jung, I. C., Kim, D. W., Moon, G. I., Kang, S. J., Kim, K. Y., and Moon, Y. H. (1998) Effects of freezing temperature on quality of vacuum packaging freezed beef. Korean J. Food
Nutr. 11, 409-415.

19. Kim, J. H., Cho, S. H., Seong, P. N., Hah, K. H., Kim, H. K., Park, B. Y., Lee, J. M., Kim, D. H., and Ahn, C. N. (2007) Effect of ageing temperature and time on the meat quality of longissimus muscle from Hanwoo steer. Korean J. Food Sci. Ani. Resour. 27, 171-178.

20. Kim, Y. H., Frandsen, M., and Rosenvold, K. (2011) Effect of ageing prior to freezing on colour stability of ovine longissimus muscle. Meat Sci. 88, 332-337.

21. Kim, Y. H., Yang, S. Y., and Lee, M. H. (1988) The effect of freezing rates on the physico-chemical changes of beef during frozen storage at $-20^{\circ} \mathrm{C}$. Korean J. Food Sci. Technol. 20, 447-452.

22. Koohmaraie, M. (1990) Quantification of $\mathrm{Ca}^{2+}$-dependent protease activities by hydrophobic and ion-exchange chromatography. J. Anim. Sci. 68, 659-665.

23. Lee, E. H., Koo, J. G., Ahn, C. B., Cha, Y. J., and Oh, K. S. (1984) A rapid method for determination of ATP and its related compounds in dried fish and shellfish products using HPLC. Bull. Korean Fish. Soc. 17, 368-372.

24. National Livestock Cooperatives Federation (NLCF) (1998) Korean carcass grading standard. National Livestock Cooperatives Federation, Seoul, Korea.

25. Olson, D. G. and Parrish, F. C., Jr. (1976) Relationship of myofibril fragmentation index to measures of beef steak tenderness. J. Food Sci. 42, 506-509.

26. Olson, D. G., Parrish, F. C. Jr., and Stromer, M. H. (1976) Myofibril fragmentation and shear resistance of three bovine muscles during postmortem storage. J. Food Sci. 41, 10361041.

27. Parrish, F. C., Jr., Young, R. B., Miner, B. E., and Andersen, L. D. (1973) Effect of postmortem conditions on certain chemical, morphological and organoleptic properties of bovine muscle. J. Food Sci. 38, 690-695.

28. SAS (1999) SAS/STAT Software for PC. Release 8.1, SAS Institute Inc., Cary, NC, USA.

29. Savell, J. W., Mueller, S. L., and Baird, B. E. (2005) Review: The chilling of carcasses. Meat Sci. 70, 449-459.

30. Shanks, B. C., Wulf, D. M., and Maddock, R. J. (2002) The effect of freezing on Warner-Bratzler shear force values of beef longissimus steaks across several postmortem aging periods. J. Anim. Sci. 80, 2122-2125.

31. Shin, H. K., Lee, Y. W., Oh, E. K., and Choi, D. Y. (1994) Effects of electrical stimulation and storage temperature on ATP-related compounds of Korean native cattle meat $M$. Semitendinosus muscles. Korean J. Food Sci. Technol. 26, 343-347.

32. Sitz, B. M., Calkins, C. R., Feuz, D. M., Umberger, W. J., and Eskridge, K. M. (2006) Consumer sensory acceptance and value of wet-aged and dry-aged beef steaks. J. Anim. Sci. 84, 1221-1226.

33. Smulder, F. J., Marsh, B. B., Swartz, D. R., Russell, R. L., and Hoenecke, M. E. (1990) Beef tenderness and sarcomere length. Meat Sci. 26, 89-99.

34. Voyle, C. A. (1971) Sarcomere length and meat quality. Proceed. 17th Eur. Meeting Meat Res. Workers. Bristol, England. 
pp. 95-97.

35. Wheeler, T. L. and Koohmaraie, M. (1994) Prerigor and postrigor changes in tenderness of ovine longissimus muscle. $J$. Anim. Sci. 72, 1232-1238.

36. Wheeler, T. L. and Koohmaraie, M. (1999) The extent of proteolysis is independent of sarcomere length in lamb longissimus and psoas major. J. Anim. Sci. 77, 2444-2451.

37. Wiklund, E., Farouk, M., Stuart, A., and Dobbie, P. (2009)
Consumer evaluation of chilled-never-frozen versus chilledfrozen-thawed beef and venison. Proceed. 55th ICoMST, Copenhagen, Denmark, pp. 1206-1209.

38. Yano, Y., Kataho, N., Watanabe, M., Nakamura, T., and Asano, Y. (1995) Evaluation of beef aging by determination of hypoxanthine and xanthine contents: application of a xanthine sensor. Food Chem. 52, 439-445.

(Received 2011.9.15/Revised 2011.10.11/Accepted 2011.10.13) 